\title{
A história de vida nos processos de RVCC: leituras críticas sobre a sua construção
}

\section{The life story in RVCC processes: critical readings about its construction}

\author{
Daniela Vilaverde e Silva \\ Instituto de Educação da Universidade do Minho
}

\begin{abstract}
Resumen
Os processos de reconhecimento, validação, certificação de competências (RVCC) ganharam uma nova visibilidade no panorama educacional em Portugal, a partir do ano 2000, conferindo certificação escolar e profissional. No final do verão de 2016, estes processos passaram a ser desenvolvidos nos Centros Qualifica. É precisamente sobre os processos de RVCC, sobre a importância da história de vida dos sujeitos no processo de RVCC, que recai a reflexão, a qual se desenvolveu a partir de uma investigação num estudo de caso. $\mathrm{Na}$ investigação verificamos que o referencial de competências-chave assume um papel central na construção das narrativas biográficas individuais de cada adulto.

Palabras clave: adultos, educação e histórias de vida
\end{abstract}

\begin{abstract}
The processes of recognition, validation and certification of competencies (RVCC) gained new visibility in the educational panorama in Portugal, from the year 2000, conferring school and professional certification. At the end of the summer of 2016, these processes began to be developed in the Qualifica Centers, with a methodology different from the one used in its initial matrix. It is precisely on the RVCC processes, the importance of the subjects' life history in the RVCC process, which is reflected in the reflection, which was developed from an investigation in a case study. In the practices we observed, we verified that the reference of key competences assumes a central role in the construction of the individual biographical narratives of each adult, guiding the whole process.

Keywords: adult, education, life story
\end{abstract}

\section{Introdução}

Em Portugal, foi a partir do ano 2000 que os processos de Reconhecimento Validação e Certificação de Competências foram implementados tendo como destinatários indivíduos com mais de 18 anos de idade, conferindo certificação escolar (nível básico B1, B2, B3 e Secundário) e profissional, a partir das competências adquiridas em diferentes contextos de vida (pessoal, social, profissional), enfatizando as experiências situadas nos domínios não-formais e informais. Estes processos já assumiram várias modificações e designações. No final do verão de 2016, estes processos passaram a ser desenvolvidos nos Centros Qualifica, com uma metodologia um pouco diferente da utilizada na sua matriz inicial. É precisamente sobre os processos de RVCC, nomeadamente sobre os discursos e as práticas dos atores intervenientes do processo, em torno da importância da história de vida dos sujeitos e da ênfase discursiva conferida aos contextos educativos nãoformais e informais do adulto no processo de RVCC, que recai a reflexão que produzimos nesta comunicação, a qual se desenvolveu a partir de uma investigação (Silva, 2012) num estudo de caso - realizada num Centro Novas Oportunidades (CNO) - do distrito de Braga, no ano de 2011, onde recorremos às seguintes metodologias: entrevistas à equipa técnica, observação das etapas do processo de RVCC e análise documental de diversos portfólios reflexivos de aprendizagem. O objetivo da comunicação visa sobretudo refletir sobre a importância da história de vida nos processos de RVCC e compreender o papel e a função do referencial de competências - chave no contexto da construção das narrativas biográficas por parte do adulto no processo de RVCC nos Portfólios Reflexivos de Aprendizagem

\section{O processo de RVCC - dimensões formais}

No ámbito do Programa Novas Oportunidades, a formalização do processo de RVCC encontrou-se consagrada na Portaria n. ${ }^{\text {o } 370 / 2008 ~ d e ~} 21$ de maio. Segundo este diploma legal, o processo de RVCC baseiase em cinco etapas fundamentais: a) acolhimento, b) diagnóstico; c) encaminhamento d) reconhecimento de competências; e) a validação de competências e f) a certificação. As três primeiras fases do processo de RVCC (acolhimento, diagnóstico e encaminhamento) representam três dimensões que podem culminar num processo de RVCC ou noutra oferta educativa de certificação.

Após o encaminhamento para um processo de RVCC, o processo desenvolve-se em torno de três eixos estruturantes: o reconhecimento, a validação e a certificação. É sobre estas três dimensões que nos debruçaremos seguidamente.

De acordo com a ANQ,

"Um processo de RVCC é sempre desenvolvido num Centro Novas Oportunidades e baseia-se num conjunto de pressupostos metodológicos [i.e. Balanço de Competências, Abordagem (Auto) 
biográfica] que permitem a evidenciação de competências previamente adquiridas pelos adultos ao longo da vida, em contextos formais, informais e não-formais, e no qual se desenvolve a construção de um Portfólio Reflexivo de Aprendizagens orientado segundo um Referencial de Competências-Chave" (Gomes \& Simões, 2007:14).

Todavia, a ANQ prevê para os adultos com "lacunas em termos de competências evidenciadas [...] face ao Referencial do nível de certificação para que se candidataram", ações de formação complementar. Assim, "serão desenvolvidas ações de formação complementar (no máximo 50 horas por adulto em processo RVCC), baseadas nas Áreas de Competências-Chave dos respetivos Referenciais" (ibidem, 15).

$\mathrm{Na}$ fase de reconhecimento, "o adulto identifica as competências adquiridas ao longo da vida através do recurso a metodologia de balanço de competências" (idem, ibidem). Após esta identificação dá-se início à descodificação do Referencial de Competências-Chave (nível básico ou nível secundário)/Referencial do RVCC Profissional. Os técnicos envolvidos nesta fase são sobretudo os técnicos de RVCC e formadores, os quais podem organizar sessões de trabalho quer individuais, quer em pequenos grupos e/ou em grupos alargados de adultos. A atividade desenvolvida pelo adulto deve basear-se na construção/reconstrução do Portfólio Reflexivo de Aprendizagens (PRA) do adulto, o qual deve contar com o apoio da equipa técnico-pedagógica (definida em função do grau de autonomia que cada adulto manifesta).

A construção do PRA e os seus conteúdos devem "ser um reflexo directo das competências que o adulto detém e, se necessário, incluir registos da equipa técnico-pedagógica que explicitam a forma como determinados comprovativos aí incluídos permitem evidenciar as competências constantes nos Referenciais" (ibidem, 16). Neste contexto, o PRA é um documento importante para a identificação das competências do adulto em função do referencial de competências-chave, tendo este último um papel norteador de toda a construção do PRA. A equipa técnica deve, à medida que o adulto for construindo o seu PRA, elucidar o adulto das competências que podem ou não ser validadas.

A validação representa uma etapa intermédia entre o reconhecimento e a certificação, a qual deve "centrar-se na realização de uma sessão, na qual o adulto e a equipa pedagógica analisam e avaliam o PRA, face ao Referencial de Competências-Chave/Referencial do RVCC Profissional" (Idem, ibidem).

Esta sessão é fundamental para a realização de um balanço do processo e progressão do adulto. Desta sessão, o adulto pode ser encaminhado para o júri de certificação ou para a formação complementar. Pode igualmente ser encaminhado para uma entidade formadora, para um percurso de qualificação (formação contínua, Curso EFA, formação no posto de trabalho, auto formação) e, neste último caso, a equipa do Centro Novas Oportunidades deverá "validar as competências que foram comprovadamente evidenciadas num Júri de Certificação, com a presença de um avaliador externo" (ibidem). O processo de RVCC termina com o júri de certificação.

\section{A história de vida e o referencial de competências- chave}

No início do processo, o trabalho das técnicas assenta na desconstrução da ideia de que o processo de RVCC incide na demonstração das experiências ou no reconhecimento de competências, distanciando-se da atividade do ensino. Esta ideia foi repetida ao longo de várias sessões e reforçada também nas entrevistas realizadas, como demonstra o excerto:

"Portanto, outra das minhas funções é esclarecer, o que é que vai acontecer, o que é isto! Embora a [nome da técnica] já lhes tenha explicado o que é o processo RVCC, eu vou explicar mais detalhadamente, e a partir daí faço o acompanhamento, sempre, da construção do portfólio, o que vai ser necessário colocar no portfólio, tendo sempre muito cuidado para dizer que isto não é ensinar, principalmente nesta primeira fase, não é ensinar, é um processo de demonstração de reconhecimento de competências" (excerto da entrevista $n^{\circ} 5$ ).

Nesta clarificação é importante destacar a centralidade da construção do PRA no processo de RVCC. É consensual entre as entrevistadas que a exposição de conteúdos proporcionada pelas primeiras sessões constitui algo confuso para os adultos, apesar de toda a empatia travada quer das técnicas quer das formadoras, como elucidam os excertos:

"As sessões de esclarecimentos são muito complicadas, é muita informação e logo no início digo 'Atenção é muito provável que cheguem ao final desta sessão e queiram desistir, porque eu vou-vos dar muita informação. Vocês vão ficar extremamente confusos! Não se assustem com isto. É mesmo assim. Na próxima sessão vocês estão mais descansados, respirem fundo e tornase mais fácil', portanto aviso-os logo que se vão sentir mal no final daquela sessão. É falar em áreas, é falar em competências" (excerto da entrevista $\mathrm{n}^{\circ}$ 5).

Portanto, embora discursivamente se privilegie o afastamento com o paradigma escolar, no campo da acção concreta encontramos várias nuances que nos aproximam deste paradigma, como, por exemplo, a componente expositiva na apresentação do referencial de competências-chave. Seguidamente, as sessões são destinadas à apresentação do referencial de competências-chave pelas formadoras. Também estes atores corroboram o papel transmissivo que revestem estas primeiras sessões, as quais podem colocar os adultos,

"Confusos, muitas vezes! Não é só com uma sessão que conseguem entender o referencial... o de TIC não! É muito fácil de explicar, quem sabe, sabe, quem não sabe, não sabe. Quem não sabe, 
tem que ter formação e ponto. O de matemática não, porque é um referencial muito extenso, muito elaborado, alguns podem saber algumas coisas, outros podem saber outras, é muita informação, por vezes, faz-lhes muita confusão! Tem que ser explicado devagarinho. Agora temos duas sessões para explicar" (excerto da entrevista ${ }^{\circ} 4$ )

Estas primeiras sessões, pelo seu carácter transmissivo, pelo papel que formadoras e técnicas assumem e pelo papel passivo do adulto, onde os conteúdos presentes no referencial de competências-chave assumem uma centralidade fundamental na primeira parte do processo.

Após o conhecimento do referencial, a técnica de RVCC auxilia os adultos na construção da "narrativa autobiográfica", onde o adulto procura descrever alguns momentos da sua vida que vão ao encontro do referencial. Depois desta fase, inicia-se a fase da integração das áreas de competências-chave do referencial na história de vida dos adultos pelas formadoras, ou seja, a fase do reconhecimento.

Uma das formadoras descreve esta fase de reconhecimento do seguinte modo:

"Primeiro explicamos ao adulto o que pretendemos que ele demonstre no seu portfólio das competências que procuramos ver, à luz do referencial; dentro, por exemplo, do referencial de Tecnologias de Informação e Comunicação, tento ver o que é que o adulto sabe fazer a nível de informática, a nível de processamento de texto, do Word, da internet, a nível de pesquisa, a nível de enviar uma mensagem, daquelas funcionalidades do Messenger, do Facebook e a nível do Excel, da folha de cálculo. Isto na parte de TIC, é o que nós procuramos ver, o que é que o adulto sabe fazer a nível de informática, a nível de Tecnologias de Informação e Comunicação, de acordo com o referencial. Poderá ser para um nível de $6^{\circ}$ ano ou de $9^{\circ}$ ano, consoante os adultos com que trabalhamos, consoante o nível de escolaridade que tem. Em matemática, da mesma maneira. Procuro ver se o adulto tem os conhecimentos do referencial. Posteriormente, fazemos um reconhecimento destas competências"(excerto da entrevista $\left.\mathrm{n}^{\circ} 4\right)$.

O reconhecimento, no campo da acção concreta, baseia-se na identificação dos conhecimentos do adulto com o referencial de competências-chave, sendo a primeira fase deste reconhecimento a averiguação dos conhecimentos inscritos no referencial de competênciaschave por parte do adulto. Na segunda fase do reconhecimento, o adulto terá de iniciar a construção do seu PRA em função dos conhecimentos que possui do referencial, integrando-os nas diferentes dimensões da sua vida. Portanto, a história de vida tem de ir ao encontro do referencial pré-definido. Todavia, a leitura do referencial pode ser definida a partir de exemplos concretos do quotidiano da vida do adulto, como explica a seguinte entrevistada:
“O adulto constrói o seu portfólio, em que vai tentar demonstrar as competências que tem. Em matemática, poderá, por exemplo, pegar numa fatura e tentar interpretar essa fatura, explicar o que diz nessa fatura, tentar explicar como é que se calcula um IVA...Por exemplo, com um recibo de vencimento que tenha, tentar calcular a percentagem de quanto desconta para a Segurança Social...Sempre integrado na vida dele" (excerto da entrevista $\left.n^{\circ} 4\right)$.

Concluída esta fase do reconhecimento, o PRA é submetido a uma primeira validação, a qual é designada de revisão do portfólio e integra vários procedimentos, desde a análise pela equipa do PRA, à reunião da técnica com o adulto até à sessão de validação. Este processo é descrito da seguinte forma:

"A sessão de comunicação de resultados e a sessão de validação, ou seja, nós tivemos durante o processo uma entrega inicial do portfólio que é chamada a versão primeira versão do portfólio. $\mathrm{O}$ portfólio foi analisado por todos os elementos da equipa ao pormenor, é feito um parecer sobre os elementos que faltam, que devem ser melhor trabalhados, o que deve ser colocado no portfólio para o enriquecer, etc... E, depois, então há uma sessão da técnica com o adulto a explicar esses elementos que são necessários trabalhar e explicar aquilo que foi escrito. $\mathrm{O}$ adulto vai então trabalhar melhor o portfólio, para o entregar numa versão definitiva, a partir daí a equipa analisa e é marcada uma sessão de validação, ou seja, é nessa fase que vamos dizer se validou aquelas áreas, as 4 áreas, se não validou que áreas é que foram validadas" (excerto da entrevista $n^{\circ} 5$ ).

A validação significa que o adulto conhece as unidades presentes no referencial de competências-chave e demonstra esses conhecimentos no seu PRA. Todavia, em situações em que o adulto não conhece o referencial, a formação complementar emerge como uma solução a implementar e auxiliar deste processo, como explica esta entrevistada:

"temos diversas unidades, por exemplo, Linguagem e Comunicação, temos a unidade A/B/C/D e depois valida a unidade ou não. Imagine que o adulto valida a unidade $\mathrm{A}$ a $\mathrm{B}$ e a $\mathrm{D}$, a C não valida, ora vai ter que frequentar formação complementar para adquirir competências na unidade $\mathrm{C}$ e depois então fica com tudo validado, no básico é tudo mais simples, não há essa creditação" (excerto da entrevista $n^{\circ}$ 5).

A formação complementar vem auxiliar o próprio processo de RVCC, sobretudo na formação exigida pelo referencial de competências-chave. Posteriormente, e após toda a tramitação deste processo, o adulto entrega a versão final do PRA e na sessão de validação são comunicados os resultados do seu trabalho, sendo que no caso de o PRA se encontrar validado é conduzido para o júri de certificação. 
O referencial de competências-chave nos processos de RVCC é definido pelo Ministério da Educação como "um conjunto de capacidades, conhecimentos e saberes que possibilitam aos cidadãos nas sociedades contemporâneas, atuarem de modo eficaz nas diferentes esferas de relação interpessoal e/ou institucional (privada, profissional, com as instituições e com a sociedade que os rodeia e sua evolução)" (DGFV, 2006:13). Trata-se, portanto de um "instrumento para a educação e formação de adultos, face ao qual se avaliam as competências-chave adquiridas em diferentes contextos de vida com vista à atribuição de uma certificação" (ibidem, 94).

No processo de RVCC, existem dois referenciais de competências-chave: o referencial de nível básico e de nível secundário $\left(12^{\circ}\right.$ ano). $\mathrm{O}$ referencial de competências-chave de nível básico é composto por quatro áreas de competências: Linguagem e Comunicação (LC), Tecnologias da Informação e Comunicação (TIC), Matemática para a Vida (MV) e Cidadania e Empregabilidade (CE). O referencial de competências-chave de nível secundário é constituído por três áreas: Sociedade, Tecnologia e Ciência (STC), Cultura, Língua e Comunicação (CLC) e Cidadania e Profissionalidade (CP).

Ao longo do processo de RVCC, verificamos a centralidade atribuída ao referencial de competênciaschave nas diferentes etapas do processo. No entanto, este processo também atribui, a nível discursivo, uma centralidade ao percurso de vida dos adultos, como elucidam alguns slogans alusivos ao programa: por exemplo, "A tua vida também conta". Assim, perante esta dualidade, as relações entre referencial de competências-chave e a história de vida que é contável, constituem um objeto de estudo que merece reflexão.

No âmbito do discurso oficial do Ministério da Educação, parece existir uma certa igualdade na importância atribuída à vida das pessoas e ao referencial de competências-chave, como se pode deduzir deste excerto:

"As aprendizagens decorrentes da formação experiencial dos candidatos constituem o ponto de partida dos processos de reconhecimento, validação e certificação de competências. No entanto, a experiência de vida per se não é sinónimo de competências, nem tão pouco os processos de reconhecimento, validação e certificação de competências se reduzem à mera elencagem casuística de experiências de vida. Importa, com efeito, desenvolver com e para os candidatos um trabalho de desocultação conducente à identificação das competências adquiridas a partir da experiência tendo como baluarte o Referencial de Competências-Chave para a Educação e Formação de Adultos" (DGFV, 2006:95).

No caso do estudo de caso, o discurso dominante por parte dos técnicos de RVCC no âmbito da observação não participante do estudo de caso, referia-se sobretudo à ideia de que a história de vida dos adultos viria a ter um papel preponderante na elaboração do PRA, conforme expressam as seguintes afirmações registadas no nosso diário de campo, numa sessão de apresentação do referencial: "O vosso portfólio é a vossa história de vida à luz disto [referencial de competências-chave]" ou "vocês têm de identificar dois domínios de referência por cada núcleo gerador partindo da vossa história de vida" (excertos do discurso da formadora, notas de campo). Contudo, nas sessões observadas, a maioria das sessões era destinada sobretudo à apresentação dos referenciais e das competências por parte dos formadores, enunciando os conhecimentos que deveriam ter nas diferentes áreas de competências-chave, ilustrando inúmeros exemplos significativos do quotidiano que pudessem ser mobilizados pelos adultos na construção do seu portfólio individual. Portanto, pelos dados da observação, esta aparente igualdade parece ser posta em causa, a favor do referencial. A existência de um referencial de competências chave representa ao investigador um duplo sentido: ser um documento orientador dos conteúdos no processo educativo dos formandos, podendo ser sujeito às modificações necessárias tendo em conta os interesses quer dos adultos quer do contexto ou ser um documento regulador definidor de um conjunto de competênciaschave que não poderia ser moldado de acordo com os interesses dos adultos e dos contextos onde se integram, quando solicitamos aos atores entrevistados para quantificarem a importância que atribuíam a estas duas dimensões, as respostas corroboram estes dados, conforme o excerto:

"O referencial, [...] é onde nós nos baseamos para ver se os adultos têm conhecimentos ou não, o portfólio é onde eles vão demonstrar esses conhecimentos [...] Para mim, é importante o referencial. Enquanto em áreas como cidadania, ao contar a história de vida, já consegue abranger todo o referencial, eles têm mesmo que pensar no referencial e depois pôr mesmo na história de vida porque são áreas mesmo específicas. $60 \% / 40 \%$, 60 para o referencial, 40 para a história" (excerto da entrevista $\left.n^{\circ} 4\right)$.

Para outra entrevistada, o referencial é assumido como tendo um carácter de obrigatoriedade em todo o processo, podendo este nem sempre estar em consonância com a vida dos adultos:

"A história de vida, praticamente... Sei lá... $20 \%, 30 \%$. O resto está mais direcionado para os temas que eles estão obrigados a abordar [...] O referencial é para cumprir! Eles têm que abordar, obrigatoriamente, os sete núcleos geradores. " (excerto da entrevista $n^{\circ} 3$ ).

Esta obrigatoriedade do referencial de competênciaschave condiciona a narrativa da história de vida de cada adulto, sendo o trabalho dos técnicos e dos formadores orientado para a descoberta do referencial nas narrativas das histórias de vida, como explica a seguinte técnica:

"Nós temos os referenciais, mas os referenciais são mais trabalhados com os formadores, enquanto que nós técnicas, nem sequer apresentamos referenciais, nós a partir do momento que auxiliamos e explicamos o que vai ser a historia de vida deles, em 
termos do que e que nós pretendemos que eles escrevam na história de vida deles" (excerto da entrevista $\mathrm{n}^{\mathrm{o}} 5$, negrito nosso).

Neste sentido, podemos considerar a valorização de uma história de vida ideal como aquele que é traduzida no capital cultural presente do referencial de competências-chave, o trabalho desenvolvido pelas técnicas de RVCC consiste numa confrontação entre as vivências dos adultos - a sua história de vida real - e o referencial de competências-chave - história de vida padrão/ideal.

\section{Conclusão}

O protagonismo que o referencial de competênciaschave adquire em torno do processo de RVCC é central. $\mathrm{O}$ processo de RVCC procura formalizar os saberes adquiridos através da educação não-formal e informal pelo que consideramos que se trata de um processo de formalização do não-formal e informal. $O$ papel conferido à história de vida é redutor e instrumentalizado, sendo esta valorização em função do referencial de competências-chave. Os dados da investigação denunciam que discursivamente, regista-se uma valorização em torno das histórias de vida, quer nos documentos oficiais quer nas entrevistas que realizamos no CNO. Nas práticas que observamos e nos dados das entrevistas, verificamos que o referencial de competências-chave assume um papel central na construção das narrativas biográficas individuais de cada adulto, norteando todo o processo, tendo a história de vida um peso inferior face ao referencial.

\section{Bibliografia}

DGFV (2006). Referencial de Competências-Chave para a Educação e Formação de Adultos Nivel Secundário - Guia de Operacionalização. Lisboa: Ministério da Educação.

Gomes, Maria do Carmo \& Simões, Francisca (2007). Carta de Qualidade dos Centros Novas Oportunidades. Lisboa: ANQ.

Silva, Daniela (2012). Lógicas de Ação na Educação de Adultos. Um olhar sociológico-organizacional. Braga: Universidade do Minho [Tese de doutoramento não publicada].

Legislação:

Portaria 370/2008 de 21 de maio

\section{Agradecimentos}

A investigação foi financiada pelo Centro de Investigação em Educação, do Instituto de Educação da Universidade do Minho 